\title{
A STUDY OF THE DIPHTHERIA GROUP OF ORGANISMS BY THE BIOMETRICAL METHOD.*
}

\author{
M ARY ELIZ A B ETH MORSE. \\ (Investigation for the Boston State Hospital at the Palhological Department of the \\ Hariard Medical School.)
}

The relationship of the diphtheria bacillus to the so-called "diphtheroids" and the "pseudo-diphtheria" or Hofmann's bacillus, has been frequently discussed. Much work has been done on the changes in morphology of the diphtheria bacillus under various conditions; also on the comparative cultural characteristics of the diphtheria bacillus, Hofmann's bacillus, and the diphtheroids, and on the variations in virulence of the true Klebs-Loeffler organism. Attempts have been made to transform Hofmann's bacillus into a typical diphtheria bacillus, and vice versa. A small amount of work has been done on the serum reactions in the group.

The view which has gradually come to prevail, forced largely by public health work, is that, whatever the systematic biological relationships of the organisms may be (and this is left an open question), practically at the present time the "diphtheroids" and "pseudos" should not be classified with the true Klebs-Loefller bacillus.

It was thought that the biometrical or statistical method, which has been applied with much success to the coccaccae by the Winslows, ${ }^{\text {I }}$ might prove of equal value in the diphtheria group, to determine whether or not subdivisions exist, and also what is the relationship of the "diphtheroids" and "pseudos" to the true Klebs-Loeffler organism. This method, which, briefly stated, involves the comparative study of selected characteristics in large numbers of individuals by exact and quantitative methods, has shed much light on anthropological and sociological problems. It was used first in bacteriology on a large scale by the Winslows in the study of the coccaccae, and has made possible a natural classification of the numerous members of this family. Since the Winslows'

* Received for publication July I2, Igra.

-Syslematic Relationships of the Coccaccae, 1908. 
first publication, several other articles have appeared, in which other bacteriological groups have been studied by this method. Notable among these researches are the further investigation by Winslow and Palmer ${ }^{1}$ of the intestinal streptococci, Howe's ${ }^{2}$ classification of the $B$. coli group, and Park and Krumwiede's ${ }^{3}$ work on the human and bovine types of the tubercle bacillus.

The present study was originally suggested by a diphtheria epidemic at the Boston State Hospital in 1909, and was undertaken at the instance of Dr. E. E. Southard, pathologist to the Massachusetts state hospitals. The cultures have been obtained from the Boston and Danvers State Hospitals; the Bacteriological Laboratory of the Boston Board of Health, through the kindness of Dr. B. L. Arms and Miss E. M. Wade; from the Research Laboratories of the New York Board of Health; the Hoagland Laboratory, Brooklyn; the Chicago Board of Health; the Johns Hopkins Hospital; the New England Hospital for Women and Children, and from other scattered sources too numerous to mention. The writer has had throughout the personal assistance and interest of Professor Winslow, and is also indebted to Dr. Henry P. Frost, superintendent of the Boston State Hospital.

In the diphtheria group are usually included, in a loose way, the Klebs-Loeffler bacillus, Hofmann's bacillus, and the "diphtheroids," the last a collection of incompletely and unsystematically described forms, which includes the xerosis bacillus and all organisms bearing any morphological resemblance to the true diphtheria bacillus.

The first criterion by which bacilli were selected for the present study was necessarily morphological. All organisms which could be collected from throat cultures and pathological conditions, and which bore any morphological resemblance to the Klebs-Loeffler bacillus were worked out, provided that they were also grampositive and non-motile.

The following tests were found most suitable and were adopted:

Morphology.-This comprised a study of 24 -hour serum cultures, the presence of Neisser's granules, and the development of involution forms.

s Jour. Infect. Dis., toto, 7, p. x.

2 Science, N.S., 1912, 35, p. 225.

3 Jour. Med. Res., I910, I8, p. 205. 
The morphological classification of the diphtheria bacillus is admittedly a matter of dispute, not only on account of its pleomorphism but also because of the subjective element which enters into one's estimation of the frequency and value of the different forms. It was decided not to use Wesbrook's detailed classification in this work, as the object was not to diagnose for public health purposes, but to ascertain whether or not certain morphological types of culture could be correlated with other characteristics. The cultures therefore were grouped broadly on the basis of 24 -hour growth on serum as to the predominating type of organism. Our experience agrees with that of Williams ${ }^{\mathrm{I}}$ that the morphological individuality of a culture is retained tenaciously under good conditions. It was found that all the strains collected could be divided into six morphological types, which formed the most satisfactory basis for a preliminary study of the group.

These types of culture may be defined as follows:

I. Cultures showing mostly slender curved bacilli of varying length, with metachromatic granules. The bacilli develop characteristic involution forms with swollen ends and irregularly staining protoplasm.

II. Cultures composed chiefly of long, curved, segmented, or barred bacilli, which often develop later into large bizarre "Indian-club" or "comma" forms.

III. Cultures in which solid and wedge-shaped bacilli predominate, although small granular and barred forms are also present and involution forms similar to those of type I appear later.

IV. Cultures showing small, thick forms, solid, barred, or wedge-shaped. These are smalker and show less variation in form than organisms of the preceding types, and do not stain as well. Neisser's granules are abundant but are small and indistinct. A marked peculiarity is the fusion of the bacilli in serum cultures at the end of several days into poorly staining masses, throughout which are scattered large, thick, intensely staining bacilli.

V. Cultures composed of large, thick, curved forms with regular, sharply outlined segments. These bacilli are larger and thicker than those of any of the foregoing classes except II, and they stain very clearly. Neisser's granules are numerous, large, and of ten of irregular shape. This type may develop the same involution forms as IV, but more often the bacilli remain separate, showing only an increase in size and more irregularity in staining.

VI. Cultures showing well-stained, usually straight bacilli, solid, wedge-shaped, or barred. These are shorter, and more uniform in appearance than those of type III. The 24-hour cultures of ten resemble closely type IV. Neisser's granules, however, are absent, and the organisms usually retain their original morphology and staining properties well, and do not develop the involution forms characteristic of the other types.

These morphological classes will be referred to by number.

× Jour. Med. Res., Igo2, 3, p. 83 . 
The photomicrographs, illustrating the six morphological types in the diphtheria group, are made from specimens from 24 -hour serum cultures, stained with Loeffler's methylene blue; $\times 1,500$.

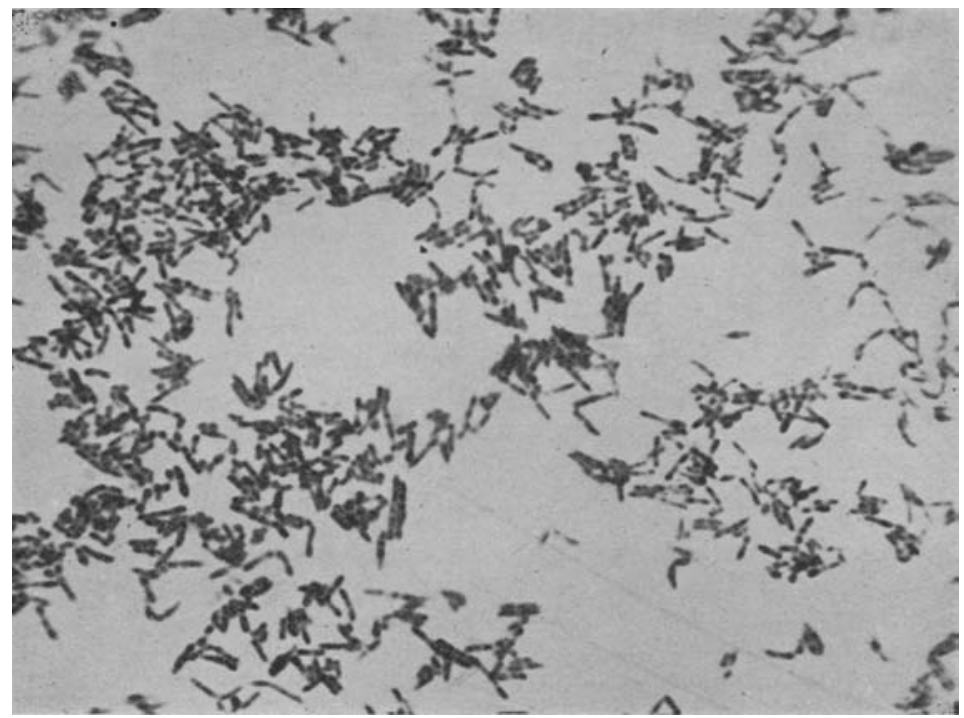

FIG. I, TYRE I

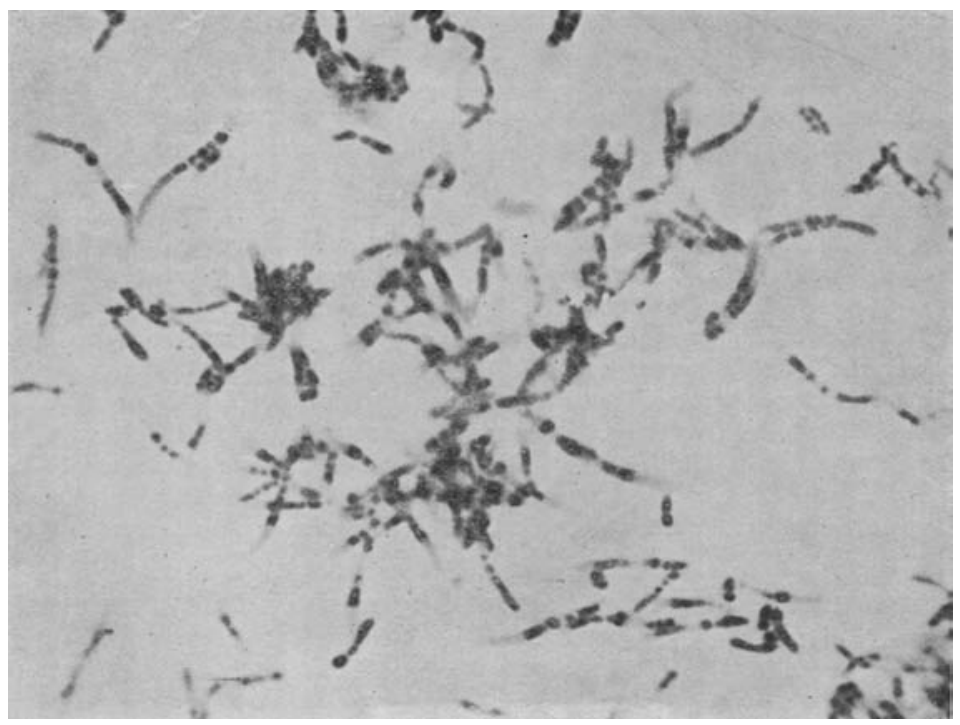

FIG. 2, TYPE 2. 


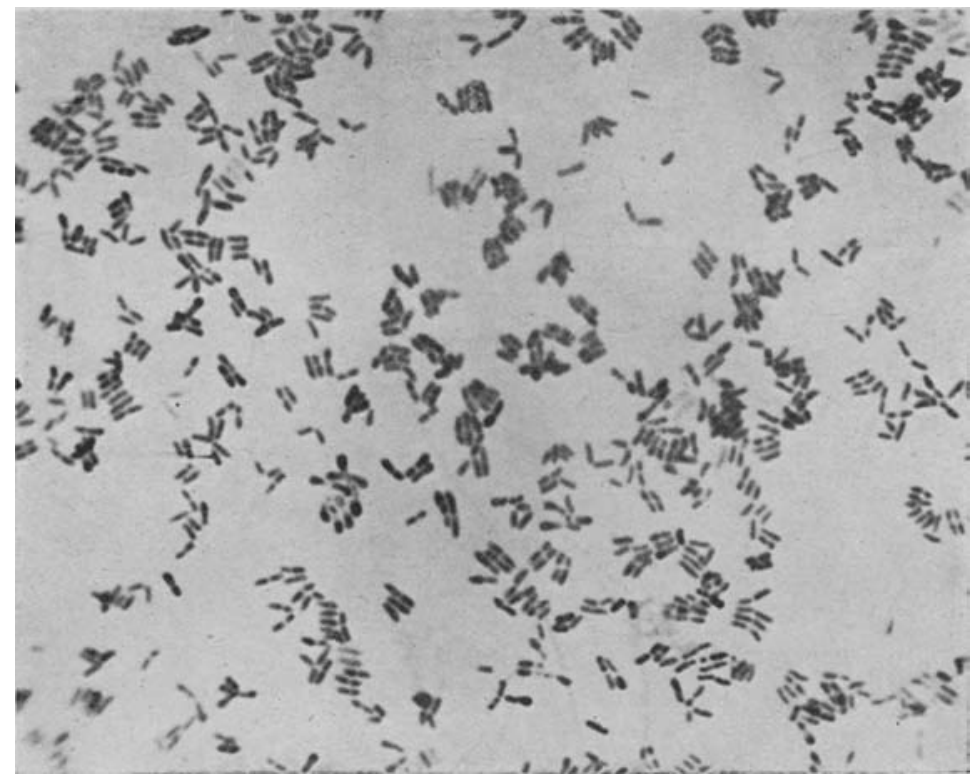

FIG. 3, TYPE 3.

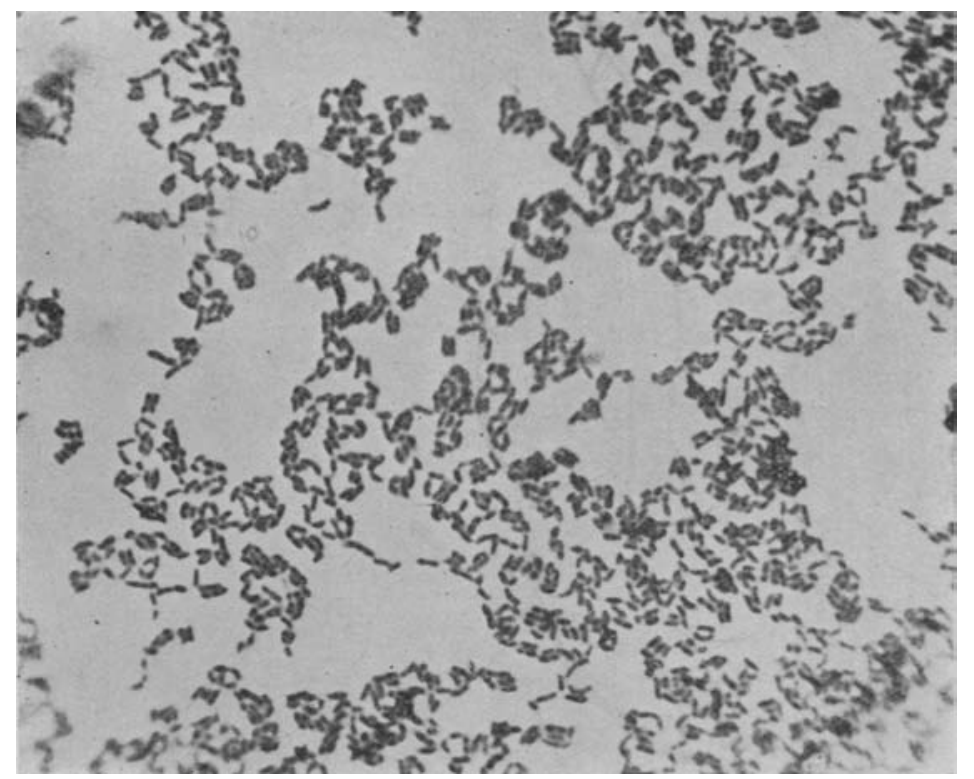

Fig. 4, TYPE 4. 


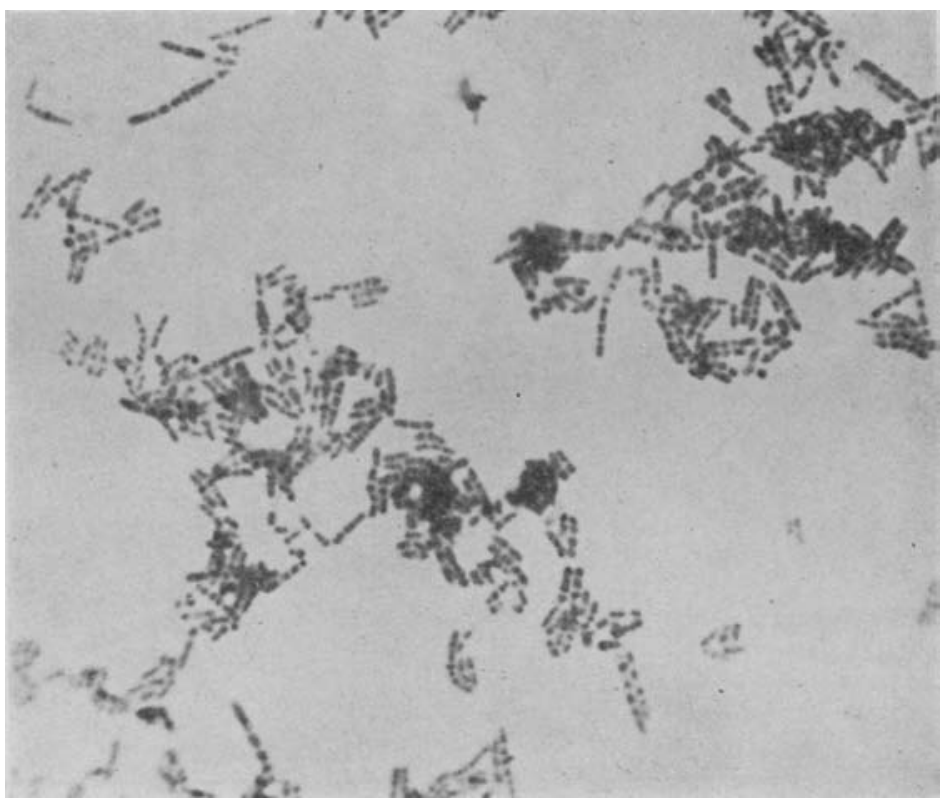

Fig. 5, TyPE 5.

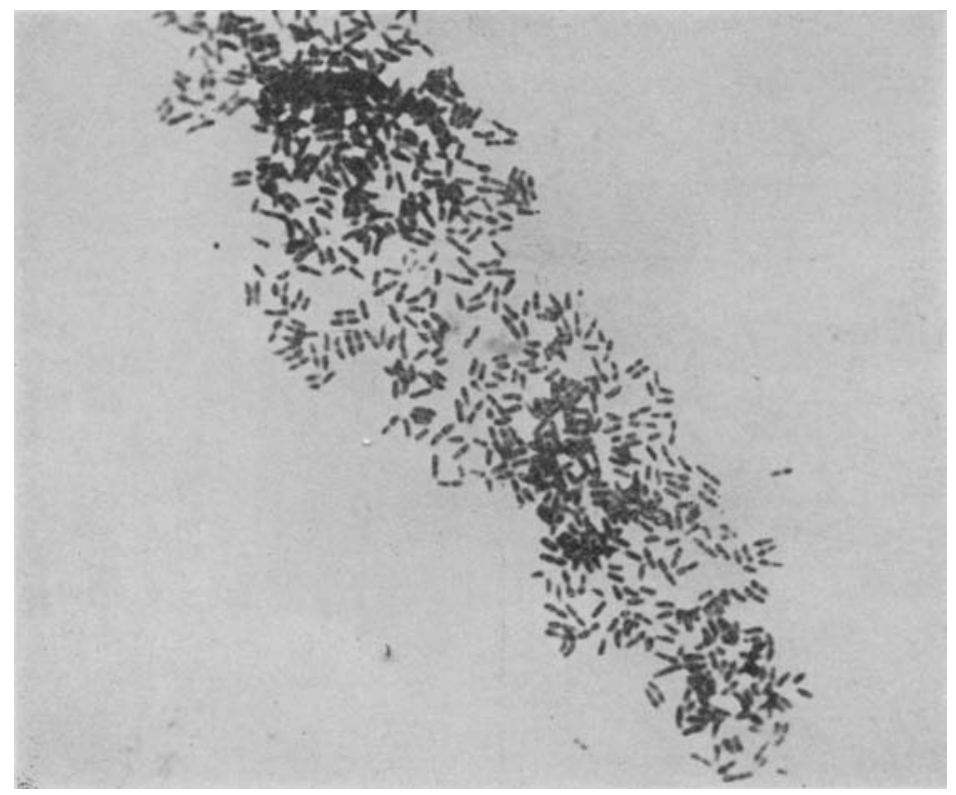

FIG. 6, TyPE 6. 
It must be emphasized in the beginning that this grouping can be only approximate, as every culture is a mixture of types; also, that the diagnosis of the type cannot be made with certainty in every case from a methylene blue stain of the 24 -hour culture alone, but that the presence of granules and the development of involution forms must also be taken into account. This classification, however, does bring out important differences in cultures, which can be correlated with other characteristics.

Obviously, types I and II represent the usual granular and segmented forms of the diphtheria bacillus. Type III is closely related both to $I$ and to IV. Types IV and $V$ correspond to the common forms of "diphtheroids," and VI to Hofmann's bacillus.

Acid production.-The acid production was quantitatively determined by titration in one per cent dextrose, maltose, saccharose, dextrin, and glycerin broth. Dextrose was chosen as a representative of the glucose group, maltose and saccharose of the cane sugar group, dextrin of the cellulose group, and glycerin as a triacid alcohol. Although dextrin is a mixture and probably of somewhat variable composition, it seemed wise to use it in view of the large amount of work done on its fermentation by the diphtheria bacillus, and the varying results obtained by different observers. Merck's "highest purity" products and c.p. glycerin were used.

The sugars were added to the broth after the latter had been sterilized. A ro per cent solution of the various carbohydrates in distilled water was heated ro minutes in the Arnold sterilizer and added in appropriate amounts to sugar-free broth having a reaction of 0.5 per cent alkaline. The broth was then tubed out aseptically and incubated three days before use. Glycerin was added without sterilization.

A series of ro organisms was titrated in each of the carbohydrates every other day for 20 days, to determine at what period, on the average, the maximum acidity occurred. Thereafter the cultures were titrated on these particular days. It was found that the maximum acidity for dextrose and saccharose occurred on the average on the 13 th day, for maltose and dextrin on the eighth or ninth, and for glycerin on the ${ }_{1} 5$ th or 16 th. The method of titration 
was as follows: the tubes were put for five minutes in boiling water 5 c.c. of the broth were then removed with a graduated syringe, 45 c.c. of hot water added, and the mixture titrated immediately with $N / 20 \mathrm{NaOH}$; phenolphthalein being used as indicator. Two tubes were titrated for each strain, and their average taken. Two sterile blanks were put through with each lot, and the average of their acidity subtracted from that of the inoculated tubes. No culture which did not show a good growth was titrated, and the tests were repeated whenever there seemed to be reason to doubt their accuracy.

Fermentation reactions with several other substances were tried on a small scale, but were discontinued. Galactose and levulose gave results very similar to dextrose. Inulin and mannite were not decomposed by any strains studied.

The stability and uniformity of fermentation reactions are of vital importance for their use in classification. These points have been tested, first, on cultures of the same strain from different sources (Park No. 8 from three different places, No. 6I of the American Museum of Natural History, and No. 45 of the New York Health Department - the same strain); second, on different colonies from the same culture; and third, by repetition of the tests on different generations of the same culture; at intervals varying from a week to a year.

It has been found that there usually is qualitative uniformity of reaction, but considerable quantitative variation. In other words, cultures of the same strain from different sources, and of different colonies from the same culture show as a rule the same reaction. The exception to this rule is glycerin, in which, of two tubes put through at the same time, one occasionally may be alkaline, the other highly acid. In dextrose, maltose, and saccharose there is, on the other hand, a marked uniformity.

The fermentation reactions also remain permanent for a long period under laboratory cultivation, i.e., a strain does not easily lose fermentative powers or acquire new ones.

There are frequently, however, considerable differences in the amount of acid formed even by the same strain in quickly repeated tests, under identical conditions. These variations are shown with 
glycerin, as has been noted above, and in a lesser degree with dextrin.

Virulence.-The virulence was tested by the subcutaneous inoculation of young guinea-pigs ( $150-250 \mathrm{gms}$.) with 0.5 per cent of their body weight of a 48-hour culture in sugar-free broth having an initial reaction of minus 0.5 per cent. Virulence was tested as soon as an organism had become accustomed to the medium and was growing well. No cultures were used in which growth was not fairly abundant. Only those strains were considered virulent which produced death of the animal with characteristic lesions within four days. Organisms giving merely a local reaction were classed as non-virulent.

Twenty-eight strains of diphtheroids were inoculated in the same manner as the diphtheria bacilli, and were found to be totally avirulent. The remainder were not tested. Twenty-one strains of Hofmann's bacillus were also tested for virulence, with negative results. No examples of Hamilton's ${ }^{x}$ virulent pseudo-diphtheria bacillus have been found.

Toxin production.-Toxin production was not used as a routine procedure but as an aid in placing certain doubtful non-virulent bacilli. The method used was that of Rosenau, described in "The Immunity Unit for Standardizing Diphtheria Antitoxin."”

Chromogenesis.-Chromogenesis appears to be of some value, chiefly among the diphtheroids, though it is not as strikingly correlated with other characteristics as among the coccaccae. It was studied in serum cultures, as the colors were found to develop more characteristically on this than on other media. On agar the diphtheroids showed a white growth with sometimes a pink or yellow tinge. Contrary to experience with many organisms, potato did not prove satisfactory, as on it the diphtheroids formed a noncharacteristic grayish-yellow growth with brown discoloration of the potato. Nährstoff gave the same results as plain agar. The chromogenesis varies somewhat with the alkalinity of the serum, being most marked when it is alkaline. That used in this work had a uniform reaction of 0.8 per cent alkaline.

sour. Infect. Dis., 1904, I, p. 690 .

- Rosenau, M. J., "The Immunity Unit for Standardizing Diphtheria Antitoxin," Hygienic Laborasory of Public Health and Marine Haspilal Service, Bull, 21, April, rgo5. 
The following color-scheme expresses the shades found in serum cultures, and has therefore been adopted for correlation of chromogenesis with other characteristics: colorless, white, gray, yellowwhite, yellow, and salmon-pink. The color was noted at the end of four days' growth at $37.5^{\circ}$.

Vigor of growth.-The vigor of the growth was noted in 24-hour and four-day cultures. Among the diphtheria bacilli, the differences were not great after the strains had become accustomed to the medium. A few strains, however, remained persistently feeble, and soon died out. Two varieties of diphtheroids grew quickly and abundantly, a third was characterized by slow and scanty growth. The degrees of surface growth have been classified as scanty, medium, and heavy.

Fixation of complement.-This part of the work will form the subject of a separate report.

Two hundred and ninety-five strains were examined, divided among the morphological classes as follows: type I, II2; II, 52; III, $25 ; \mathrm{IV}, 48 ; \mathrm{V}, 32 ; \mathrm{VI}, 26$. As a rule only one strain was isolated from each source and one set of titrations made on each strain.

\section{RESULTS.}

A preliminary orientation is obtained by a glance at Table I, which shows the qualitative relationships between the six morphological groups and the other characters studied.

TABLE I.

Relationship of Morphological Types to Other Characters.

\begin{tabular}{|c|c|c|c|c|c|c|c|c|c|}
\hline \multirow{2}{*}{ TYPE } & \multicolumn{5}{|c|}{ Acid Production in } & \multirow{2}{*}{$\begin{array}{l}\text { VIRU- } \\
\text { LENCE }\end{array}$} & \multirow{2}{*}{$\begin{array}{l}\text { Toxin } \\
\text { ProDuc } \\
\text { TION }\end{array}$} & \multirow{2}{*}{$\begin{array}{l}\text { Chromo- } \\
\text { GENESIS }\end{array}$} & \multirow{2}{*}{$\begin{array}{l}\text { VIGOR OF } \\
\text { GROW TM }\end{array}$} \\
\hline & Dextrose & Maltose & Glycerin & $\underset{\text { rose }}{\text { Saccha- }}$ & Dextrin & & & & \\
\hline $\begin{array}{l}\text { II. } \\
\text { III. }\end{array}$ & + & $\begin{array}{l} \pm \\
\pm\end{array}$ & \pm & $\bar{z}$ & $\begin{array}{l} \pm \\
\pm \\
-\end{array}$ & $\begin{array}{l}+ \\
\pm \\
F\end{array}$ & \pm & $\begin{array}{l}\text { Gray } \\
\text { Gray } \\
\text { Gray, often }\end{array}$ & + \\
\hline IV. & \pm & $\bar{t}$ & $\overline{ \pm}$ & $\stackrel{+}{ \pm}$ & $\overline{-}$ & $\overline{-}$ & $\overline{-}$ & $\begin{array}{l}\text { with pink tinge } \\
\text { Salmon-pink } \\
\text { Yellow or }\end{array}$ & ++ \\
\hline VI. & - & - & - & - & - & - & - & White & + \\
\hline
\end{tabular}

The sign \pm indicates that positive and negative results were obtained in about equal proportions; the sign $\mp$ that while the results in general were negative some positive ones were obtained. 
The most important deductions from the table are as follows: there is a decrease in fermentative powers and virulence in passing from morphological groups I to VI; the chromogenic cultures belong to IV and V; and group III is intermediate in character in fermentation reactions, virulence, and chromogenesis.

The curves of acidity in the five carbohydrates for all the organisms investigated may also serve as an introduction to a more extensive study.

The curve in dextrose broth (Chart I) shows two groups, one non-acid, the other acid-forming with its mode at $4.0-4.5$ per cent. In the first group are morphological type VI, a few non-virulent bacilli of I, II, and III, and a few bacilli of type IV. In the acid group are the majority of types $\mathrm{I}$ to $\mathrm{V}$.

In maltose broth also (Chart I) two groups, an acid and a nonacid, are apparent. The non-acid group comprises types IV and VI; the acid group contains I, II, and V. Type III is represented. in both groups.

In saccharose broth (Chart I) the curve shows two groups, one alkaline, neutral, and weakly acid, the other highly acid. Classes I, II, V, and VI and a part of III form the first group, while the latter is composed of IV and some of III.

The curves (Chart 2) in dextrin and glycerin show all organisms varying about one mode, the neutral point.

The relationship of the morphological groups to each of the characters studied will be analyzed in detail.

Correlations between morphological groups and fermentation reactions.-In dextrose broth (Table 2) the close similarity of

TABLE 2.

Correlation between Morphological Types and Fermentation of Dextrose. Acio Produced (Percentage Normal).

\begin{tabular}{|c|c|c|c|c|c|c|c|c|}
\hline \multirow{2}{*}{ TYPES } & \multicolumn{8}{|c|}{ Number of Cultures of Each Type } \\
\hline & $\begin{array}{c}\text { Alkaline } \\
-0.0\end{array}$ & $0.0-\mathbf{r} .0$ & $1.0-2.0$ & $2.0-3.0$ & $3.0-4.0$ & $4.0-5.0$ & $5.0-6.0$ & $\begin{array}{c}\text { Above } \\
6.0\end{array}$ \\
\hline 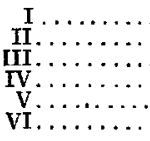 & $\begin{array}{r}0 \\
0 \\
0 \\
5 \\
0 \\
25\end{array}$ & $\begin{array}{l}4 \\
2 \\
2 \\
8 \\
3 \\
3\end{array}$ & $\begin{array}{l}2 \\
2 \\
5 \\
7 \\
7 \\
0\end{array}$ & $\begin{array}{l}5 \\
5 \\
3 \\
8 \\
4 \\
0\end{array}$ & $\begin{array}{r}34 \\
15 \\
5 \\
5 \\
7 \\
0\end{array}$ & $\begin{array}{r}33 \\
17 \\
7 \\
6 \\
11 \\
0\end{array}$ & $\begin{array}{r}7 \\
10 \\
2 \\
3 \\
5 \\
0\end{array}$ & $\begin{array}{l}7 \\
5 \\
2 \\
6 \\
1 \\
0\end{array}$ \\
\hline
\end{tabular}


groups I and II is apparent, both having their modes at 3.0-5.0 per cent. Groups III and V resemble the first two. Group IV

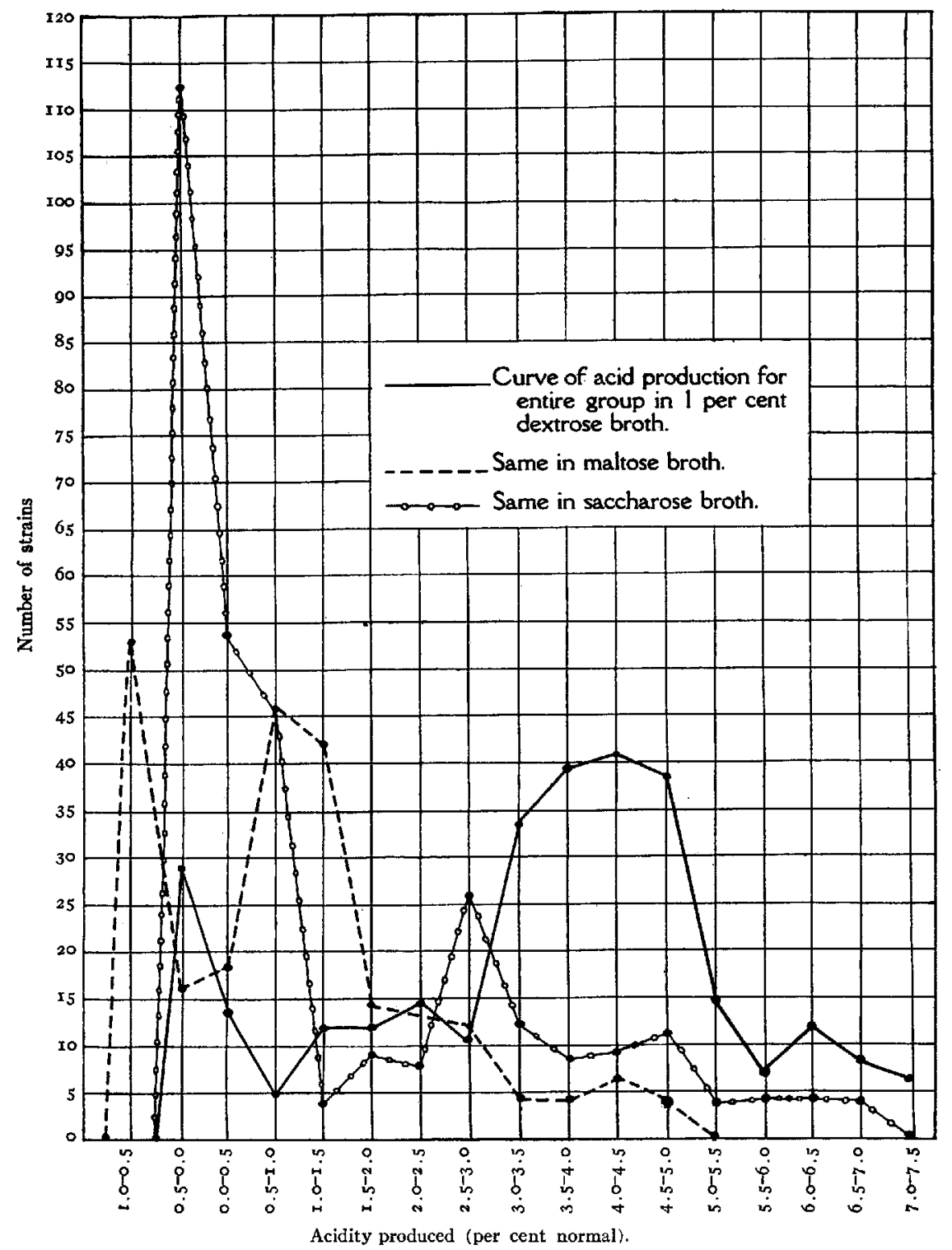


Study of Diphtheria Group by Biometrical Method 265 shows a wide range from alkalinity to high acidities. In VI all cultures are below I per cent acidity.

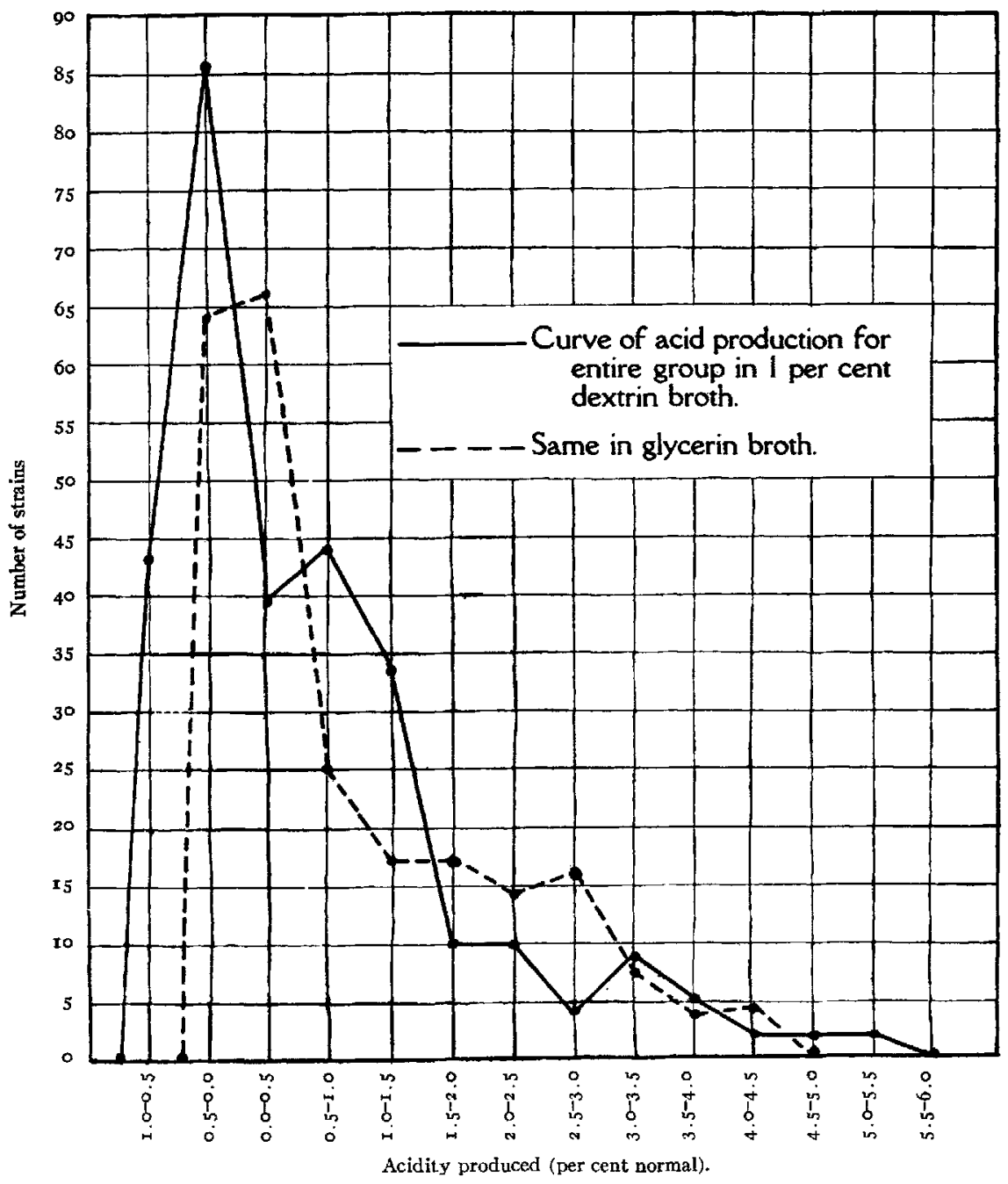

Chart 2.

No special stress can be laid on quantitative results in the fermentation of glycerin, because of the great variability of reaction to it. Table 3 , however, does bring out two important points, i.e., 
that groups IV and VI do not acidify glycerin, while V has considerable fermentative powers.

TABLE 3 .

Correlation between Morphological Types and Fermentation or Glycerin. aci Produced (Percentage Normal).

\begin{tabular}{|c|c|c|c|c|c|c|}
\hline \multirow{2}{*}{ TYPES } & \multicolumn{6}{|c|}{ Number of Cultures of Each Type } \\
\hline & $\begin{array}{c}\text { Alkaline } \\
-0.0\end{array}$ & $0.0-1.0$ & $1.0-2.0$ & $2.0-3.0$ & $3.0-4.0$ & $\begin{array}{c}\text { Above } \\
4.0\end{array}$ \\
\hline 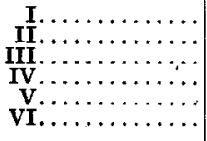 & $\begin{array}{r}19 \\
2 \\
4 \\
23 \\
5 \\
15\end{array}$ & $\begin{array}{r}36 \\
16 \\
6 \\
16 \\
10 \\
8\end{array}$ & $\begin{array}{r}20 \\
9 \\
2 \\
0 \\
3 \\
0\end{array}$ & $\begin{array}{r}\mathbf{r g} \\
8 \\
0 \\
0 \\
3 \\
0\end{array}$ & $\begin{array}{l}4 \\
2 \\
0 \\
0 \\
5 \\
0\end{array}$ & $\begin{array}{l}0 \\
0 \\
0 \\
0 \\
I \\
0\end{array}$ \\
\hline
\end{tabular}

Analysis of the results in maltose broth (Table 4) again brings out similarity between groups I and II and slight fermentative powers in III and VI. Thirty-nine, or 8I per cent of type IV are either alkaline or below I per cent acidity. Members of V, on the other hand, are strong acid-producers.

TABLE 4.

Correlation between Morphotogicat. Types and Fermentation of Maltose. Acid Produced (Percentage Normai).

\begin{tabular}{|c|c|c|c|c|c|c|}
\hline \multirow{2}{*}{ Types } & \multicolumn{6}{|c|}{ Nomber of Cultures of Each Type } \\
\hline & $\begin{array}{c}\text { Alkaline } \\
-0.0\end{array}$ & $0.0-1.0$ & $1.0-2.0$ & $2.0-3.0$ & $3.0-4.0$ & $4.0-5.0$ \\
\hline 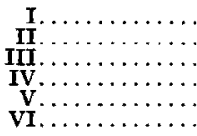 & $\begin{array}{r}0 \\
3 \\
5 \\
27 \\
2 \\
11\end{array}$ & $\begin{array}{r}33 \\
14 \\
33 \\
12 \\
5 \\
9\end{array}$ & $\begin{array}{r}37 \\
15 \\
1 \\
2 \\
3 \\
1\end{array}$ & $\begin{array}{l}4 \\
3 \\
0 \\
5 \\
3 \\
0\end{array}$ & $\begin{array}{l}I \\
0 \\
0 \\
I \\
6 \\
0\end{array}$ & $\begin{array}{l}0 \\
0 \\
\text { I } \\
\text { I } \\
9 \\
0\end{array}$ \\
\hline
\end{tabular}

In saccharose broth (Table 5) groups I, II, and VI are gathered about the neutral point. Of groups III and V, half are below

TABLE 5 .

Correlation hetween Morphological Types and Fermentation of Saccharose. Acm Produced.

\begin{tabular}{c|c|c|c|c|c|c|c|c|c}
\hline \hline \\
TyPES
\end{tabular}


Study of Diphtheria Group by Biometrical Method 267

I per cent acidity, the other half range to high acidities. Group IV is composed of strong acid-producers.

Dextrin (Table 6) is acted on to the same extent by types I and II, but is not decomposed by the last four.

TABLE 6.

Correlation hetween Morphologicar Types and Fermentation of Dextrin. Acid Prodeced (Percentage Nomal).

\begin{tabular}{|c|c|c|c|c|c|c|c|}
\hline \multirow{2}{*}{ TYPES } & \multicolumn{7}{|c|}{ Number of Cultures of Each Type } \\
\hline & $\begin{array}{c}\text { Alkaline } \\
-0.0\end{array}$ & $0.0-1.0$ & $1.0-2.0$ & $2.0-3.0$ & $3.0-4.0$ & $4.0-5.0$ & $5.0-6.0$ \\
\hline $\begin{array}{r}\mathbf{I} \ldots \ldots \ldots \\
\mathbf{I I} \ldots \ldots \ldots \ldots \\
\mathbf{I I} \ldots \ldots \ldots \ldots \\
\mathbf{V I} \ldots \ldots \ldots \\
\mathbf{V I} \ldots \ldots \ldots\end{array}$ & $\begin{array}{r}16 \\
5 \\
6 \\
27 \\
12 \\
16\end{array}$ & $\begin{array}{r}32 \\
25 \\
16 \\
12 \\
23 \\
5\end{array}$ & $\begin{array}{r}30 \\
10 \\
4 \\
3 \\
0 \\
0\end{array}$ & $\begin{array}{r}\text { II } \\
4 \\
0 \\
0 \\
0 \\
0\end{array}$ & $\begin{array}{l}8 \\
3 \\
\mathbf{1} \\
0 \\
0 \\
0\end{array}$ & $\begin{array}{l}\mathbf{I} \\
0 \\
\mathbf{I} \\
0 \\
0 \\
0\end{array}$ & $\begin{array}{l}0 \\
I \\
0 \\
0 \\
0 \\
0\end{array}$ \\
\hline
\end{tabular}

Correlations between morphological types and virulence.-A study of the relationship between morphological types and virulence for guinea-pigs brings out the fact that of type I, 57 cultures or 6 I.3 per cent were virulent and 36 or 38.7 per cent non-virulent; while of type II, I 7 cultures or 33.3 per cent were virulent, and 34 or 66.6 per cent non-virulent. Type III showed 18 non-virulent and only one virulent culture.

TABLE 7 .

Correlation between Morphological Types and Virulence for Guinea-Pigs.

\begin{tabular}{|c|c|c|c|c|c|c|}
\hline & \multicolumn{6}{|c|}{ Number of Cultures of Each Type } \\
\hline & I & II & III & IV & $\mathrm{v}$ & VI \\
\hline $\begin{array}{l}\text { Virulent........... } \\
\text { Non-virulent..... }\end{array}$ & $\begin{array}{l}57 \\
36\end{array}$ & $\begin{array}{l}17 \\
34\end{array}$ & $\begin{array}{r}\mathbf{I} \\
18\end{array}$ & $\begin{array}{c}0 \\
18 \\
\text { (tested) }\end{array}$ & $\begin{array}{c}0 \\
\text { ro } \\
\text { (tested) }\end{array}$ & $\begin{array}{c}0 \\
2 x \\
\text { (tested) }\end{array}$ \\
\hline
\end{tabular}

Six cultures of class IV and three of $\mathrm{V}$ were tested for toxin production. Injections of the filtrate from two strains of class IV produced local induration in doses of 0.1 c.c., from another strain in a dose of I.Oc.c. All of the animals recovered. Filtrates of the other six cultures were without effect in doses of I c.c.

Correlation between morphological types and chromogenesis.-The great majority ( $9 \circ$ per cent each) of cultures of types I and II were gray. There were a few colorless, white, and yellow-white variants, 
and a few ( 3 per cent each) showing a salmon-pink tinge. The proportion of the latter rose in type III to 23 per cent. In IV salmon-pink was the prevailing color ( 83 per cent), the remainder of the group being yellow, yellow-white, or white. Type $V$ is represented in all classes except gray from colorless to yellow, but, as will be seen later, it is made up of two subdivisions, slowly and scantily growing strains, showing a colorless or white growth and differing slightly in fermentation reactions from the abundantly growing yellow and yellow-white cultures.

Most of the members of type VI gave a white or yellow-white growth.

TABLE 8.

Correjation between Morphologicat Types and Chromogenesis.

\begin{tabular}{|c|c|c|c|c|c|c|}
\hline \multirow{2}{*}{ TYPE } & \multicolumn{6}{|c|}{ Number of Cultures in Each Ciass } \\
\hline & Colorless & White & Gray & Yellow-white & Yellow & Salmon-pink \\
\hline 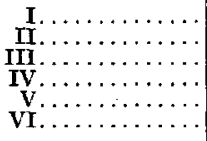 & $\begin{array}{l}3 \\
I \\
I \\
0 \\
7 \\
I\end{array}$ & $\begin{array}{r}I \\
0 \\
0 \\
1 \\
7 \\
15\end{array}$ & $\begin{array}{r}10 \mathrm{I} \\
46 \\
16 \\
0 \\
0 \\
0\end{array}$ & $\begin{array}{l}3 \\
3 \\
3 \\
3 \\
4 \\
8 \\
8\end{array}$ & $\begin{array}{l}0 \\
0 \\
0 \\
3 \\
10 \\
0\end{array}$ & $\begin{array}{r}4 \text { (tinge) } \\
2 \text { (tinge) } \\
6 \\
40 \\
0 \\
2\end{array}$ \\
\hline
\end{tabular}

Correlation between morphology and vigor of growth.-This is of limited value because, as has been said, a strain which grew poorly at first may later become accustomed to the medium, and flourish abundantly. The vigor of growth, therefore, has been estimated, not from the first culture alone, but also from successive replants.

Table 9, however, shows several important facts. The majority of cultures of type III grew heavily from the start. Strains of

TABLE 9 .

Correlation between Morphology and Vigor of Growth.

MORPYOLOGICAL TYPES.

\begin{tabular}{|c|c|c|c|c|c|c|}
\hline \multirow{2}{*}{ Surface Growth } & \multicolumn{6}{|c|}{ Numbers of Cultures of Each Type } \\
\hline & I & II & III & IV & V & VI \\
\hline $\begin{array}{l}\text { Scanty . . . . . . . } \\
\text { Medium. . } \\
\text { Heavy . . . . . }\end{array}$ & $\begin{array}{l}35 \\
44 \\
33\end{array}$ & $\begin{array}{l}18 \\
16 \\
18\end{array}$ & $\begin{array}{r}2 \\
6 \\
17\end{array}$ & $\begin{array}{r}\circ \\
3 \\
45\end{array}$ & $\begin{array}{r}13 \\
1 \\
18\end{array}$ & $\begin{array}{r}8 \\
3 \\
\mathbf{1} 5\end{array}$ \\
\hline
\end{tabular}

group IV all grew abundantly. In group V, two subdivisions are again apparent, as in Table 8 , the scantily growing cultures being 
Study of Diphtheria Group by Biometrical Method 269

colorless or white, and the heavily growing strains yellow or yellowwhite.

The numbers of groups I, II, and VI in the different classes of growth are not especially significant.

From the preceding analysis, it is clear that there are two large subdivisions in the diphtheria group. The first is composed of slender, curved, granular, or segmented bacilli (types I and II) which vary greatly in morphology and develop characteristic involution forms. The members of this subgroup form acid in dextrose and maltose, and in about half the cases in glycerin and dextrin also, but they do not act on saccharose. The prevailing color of these cultures is gray. In man and in guinea-pigs many members of this group produce characteristic lesions due to a specific toxin.

The members of the second subdivision, which includes types IV, V, and VI, show a marked morphological resemblance to each other, and a lesser resemblance to members of the first subgroup. They are thicker and more regular than the latter and do not develop the same involution forms; they are non-virulent for guineapigs and do not form the toxin characteristic of the first group. The possibility of a pathogenic action for man will be touched on later. They show differences in fermentation reactions, agreeing only in their inability to acidify dextrin. Chromogenic cultures (yellow and salmon-pink) are frequent. All degrees of growth, from scanty to very heavy, are represented. The correlated differences in fermentation reactions, chromogenesis, and vigor of growth permit a further subdivision of this group into species.

There are also a few strains which, while coinciding in most properties with the first group, show features characteristic of the second. These cultures are represented by morphological type III.

This primary subdivision is a justification by the biometrical method of the current broad classification of the diphtheria group into the diphtheria bacillus and the "diphtheroid" bacilli.

Each of these groups will be considered in detail.

FIRST SUBGROUP, THE DIPHTHERIA BACILLUS (MORPHOLOGICAL TYPES I, II, AND III).

A glance at the table of relationship between morphology and the source of the culture, i.c., whether from a clinical case, a carrier, 
or from an unusual situation or lesion, shows that, while types I and II were represented in approximately equal numbers among clinical cases and carriers, the bacilli from unusual situations were, with one exception, of type II.

TABLE IO,

Correlation between Morphology and Habitat oR Lesion.

\begin{tabular}{|c|c|c|c|c|}
\hline Type & $\begin{array}{l}\text { Pharyngeal } \\
\text { Diphtheria }\end{array}$ & $\begin{array}{c}\text { Nasal } \\
\text { Diphtheria }\end{array}$ & Carriers & Other Situations \\
\hline I. $\ldots \ldots \ldots \ldots$ & $4 x$ & 6 & 20 & I-sinus of elbow joint \\
\hline II $\ldots \ldots \ldots \ldots$ & 37 & 2 & I8 & $\begin{array}{l}\text { 2-eye } \\
\text { I-abscess of breast } \\
\text { I-sputum asthma } \\
\text { I-vagina } \\
\text { I-nose, with ozena bacillus }\end{array}$ \\
\hline III. . . . . & 5 & $\circ$ & I6 & $\circ$ \\
\hline
\end{tabular}

Cultures from unusual situations include two from the eye, and one each from a sinus leading to the elbow joint, an abscess of the breast, the sputum from a case of asthma, the vagina, and the nose, associated with ozena bacillus. The majority of cultures of type III came from carriers, and only a small proportion from clinical cases ( 6 and 5 , respectively).

In other words, diphtheria bacilli from parts of the body other than the throat and nose are more often of the segmented than of the granular type, and the small granular and solid forms are not often found in clinical diphtheria.

Correlations between sources of cultures and their virulence do not yield any new information. Of cultures taken from cases which the records sent to the Health Department showed to be cases of clinical diphtheria, 40 were virulent and 29 avirulent for guinea-pigs. Of cultures from carriers, mostly school-children, I3 were virulent and 37 avirulent. Cultures for release showed one virulent and three non-virulent. From cases of nasal diphtheria seven strains were virulent, and one non-virulent.

Five non-virulent strains were obtained from the nose, throat, and ears of scarlet fever patients. Two virulent cultures were obtained from the eye.

Cultures from unusual situations (abscess of the breast, sputum in a case of asthma, vagina) were non-virulent, with one exception- 
Study of Diphtheria Group by Biometrical Method

a strain from a sinus following a fracture. The correlation of virulence with the three morphological types has already been devel-

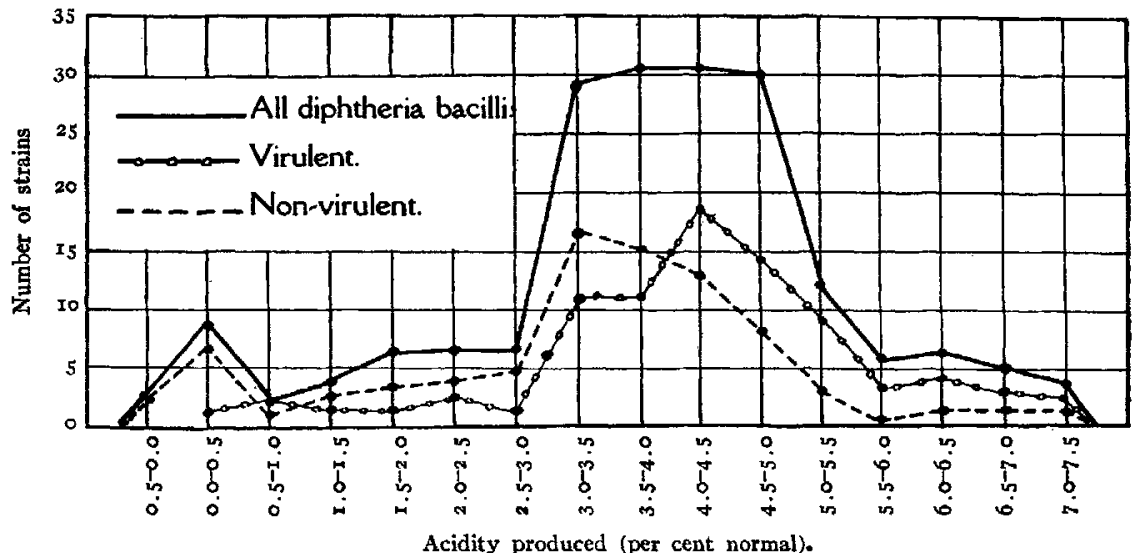

CharT 3.-Curves of acid production for types I, II, and III (diphtheria bacilli) in one per cent dextrose broth.

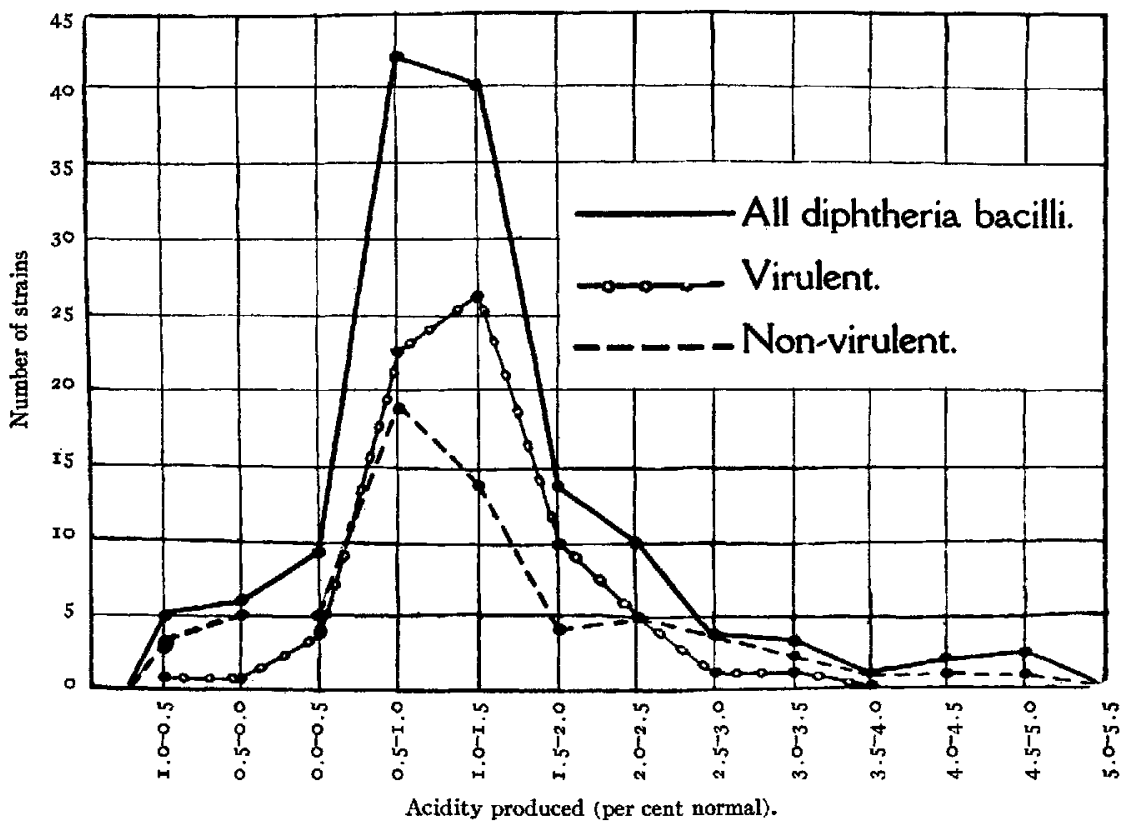

CharT 4--Curves of acid production for types I, II, and III (diphtheria bacilli) in one per cent maltose broth. 
oped. Of the granular cultures, the majority are virulent, while of the segmented two-thirds are non-virulent. The small granular type are almost all non-virulent.

The curves of acid formation for types I, II, and III (Charts 3 to 7) will be considered next. Those in maltose, saccharose, glycerin, and dextrin show only one mode. In dextrose broth, there

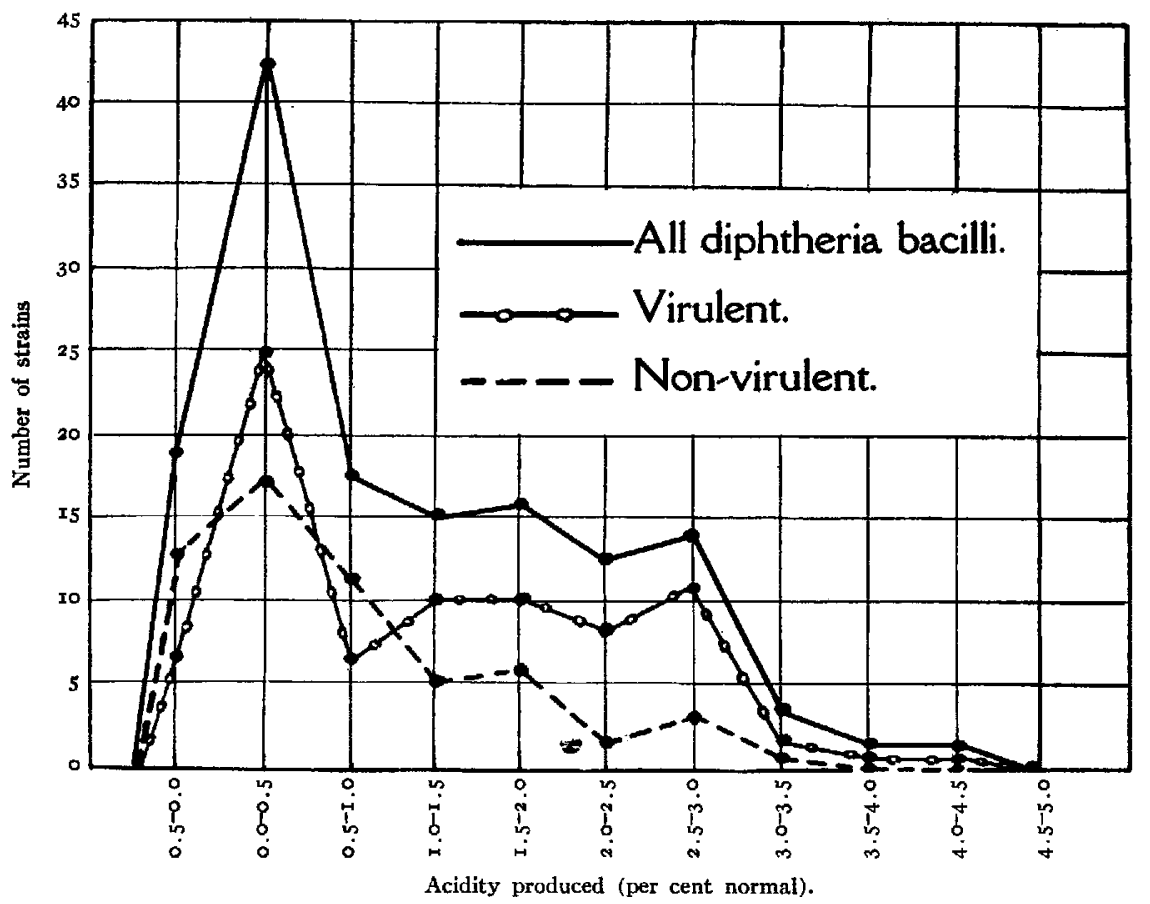

CharT 5.-Curves of acid production for types I, II, and III (diphtheria bacilli) in one per cent glycerin broth.

are two modes, a slight one at $0.0-0.5$, and the chief one at $3.0^{-}$ 5.0 per cent. Plotting the curves for virulent and non-virulent diphtheria bacilli separately brings out slight differences between the two groups. In dextrose, maltose, and dextrin, the mode for the non-virulent series falls in each case at a lower degree of acidity than that for the virulent, while in saccharose most of the bacilli forming acid are non-virulent.

Analysis of the curve in dextrose broth shows that non-virulent 
Study of Diphtheria Group by Biometrical Method

strains are chiefly responsible for the low acid group (nine nonvirulent and one virulent). The mode for the high-acid group

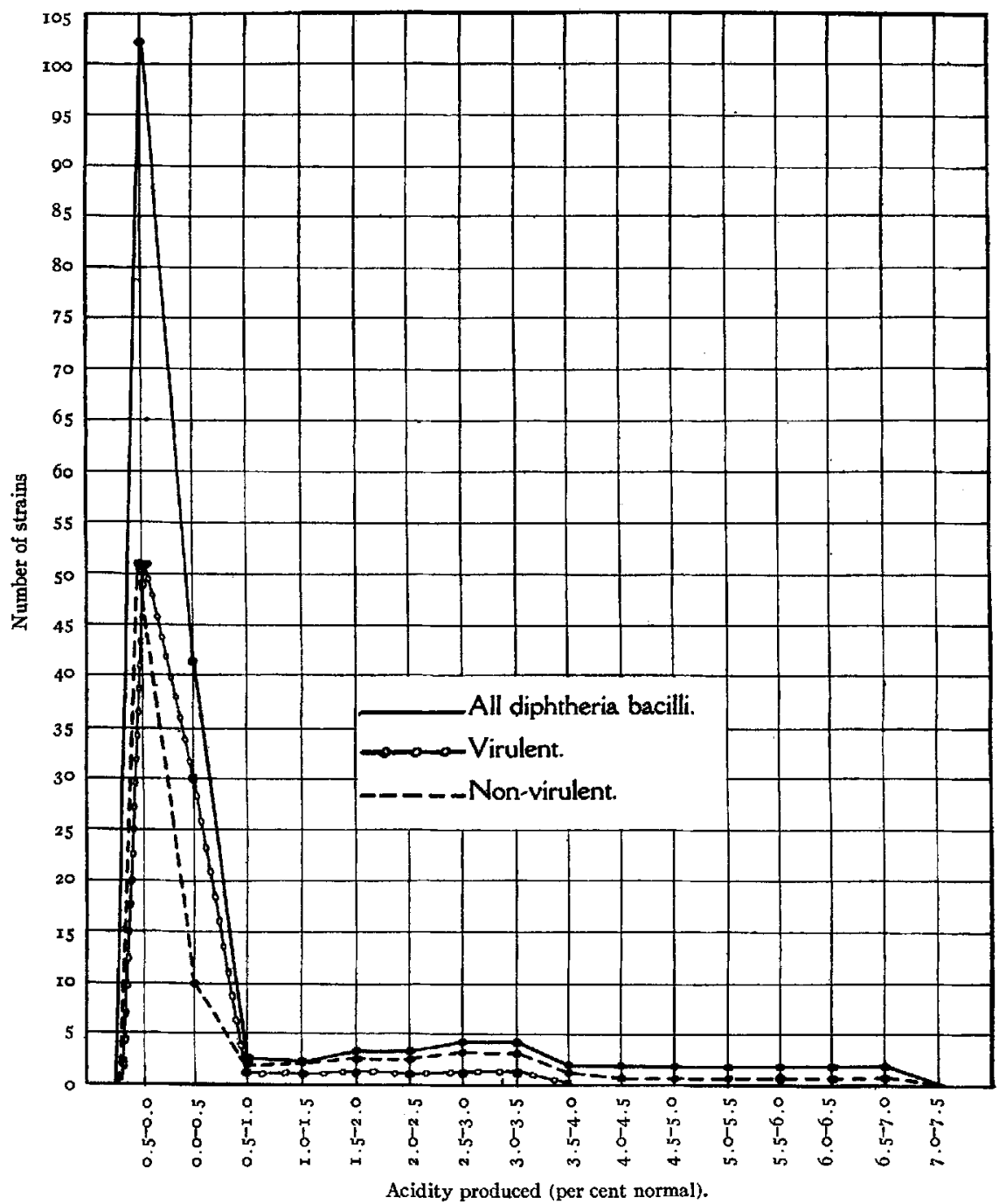

Chari 6.-Curves of acid production for types I, II, and III (diphtheria bacilli) in one per cent saccharose broth.

falls at $3.0-3.5$ per cent for the non-virulent organisms; at $4.0-$ 4.5 per cent for the virulent. 
In maltose broth, the mode for the non-virulent strains is at $0.5^{-1} .0$, for the virulent at I.O-I.5 per cent.

In dextrin broth, both virulent and non-virulent bacilli are represented to the same extent in the alkaline group, but the second mode for the non-virulent organisms is at $0.0-0.5$ per cent; for the virulent at I.O-I.5 per cent. Among the non-virulent there are no strains giving an acidity above 3.5 per cent.

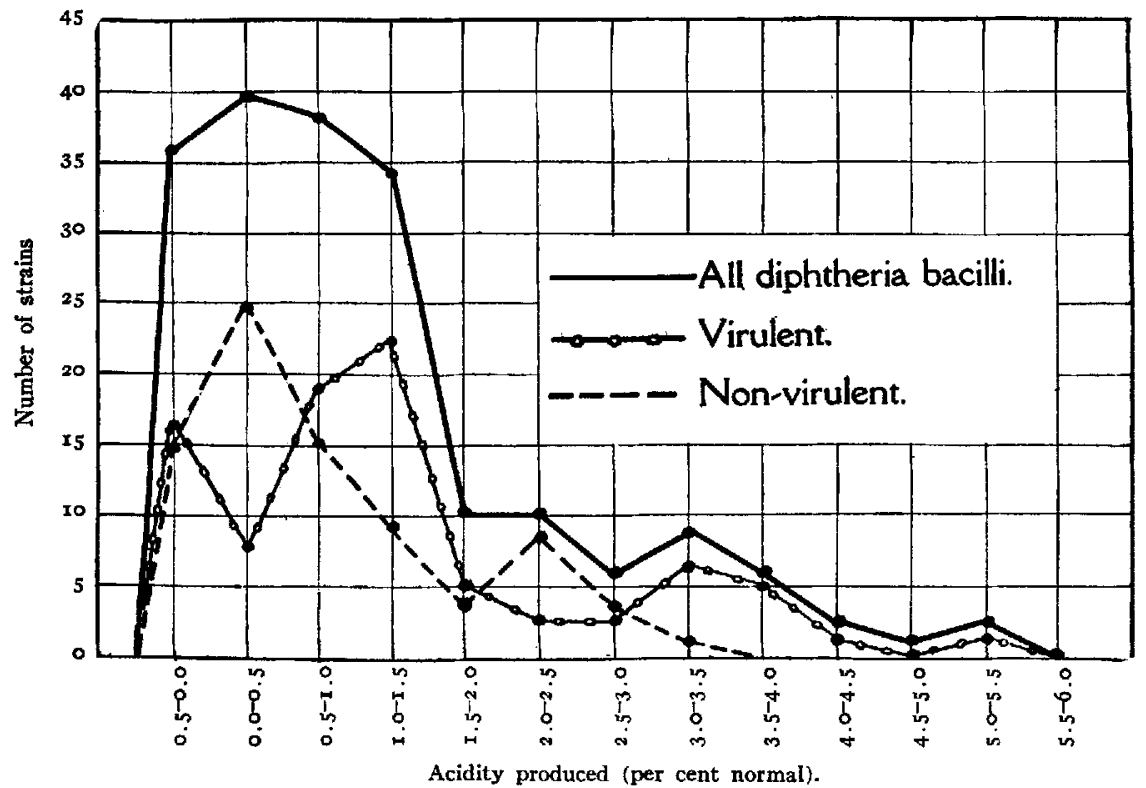

Chart 7.- Curve of acid production for types I, II, and III (diphtheria bacilli) in one per cent dextrin broth.

In glycerin broth, there is no difference between virulent and avirulent groups, the mode for both falling at $0.0-0.5$ plus.

It has been a debated point whether or not differences, morphological or biochemical, could be demonstrated between virulent and avirulent diphtheria bacilli. These results show that when a long series is examined, distinct though small differences do appear in the groups as a whole, both in morphology and in fermentative powers. In the virulent group, granular bacilli predominate, forming 76 per cent; segmented organisms form 22 per cent, and small granular and solid types about one per cent. In the avirulent 
group, granular and segmented forms are present in about equal proportions (the former 40 per cent, the latter $3^{8}$ per cent), while 2 I per cent of the group is made up of small granular and solid types. The virulent organisms have slightly greater action on dextrose, maltose, and dextrin. On the other hand, non-virulent organisms predominate among the saccharose fermenters.

It is apparent, however, that virulent and non-virulent forms are very closely related, and that the practice, common among medical workers, of limiting the term "true diphtheria bacillus" to the virulent forms, and using the expression "diphtheria-like" bacilli for the non-virulent, is in reality confusing and not justified biologically. In view of the ease with which virulence is known to be modified in other bacteria, it seems questionable whether it should be considered as having more than varietal significance.

The aberrant character of type III in relation to I and II and its similarity to type IV has been brought out. The resemblance is shown by its heavy growth, often with a pink tinge, its relatively slighter action on dextrose, maltose, and glycerin, on the one hand, and, on the other, its frequent fermentation of saccharose. These strains should perhaps be classed with diphtheroids rather than with diphtheria bacilli, but it is clear that no sharp line can be drawn biologically between these organisms and the typical diphtheria bacillus on the one side and group IV of the diphtheroids on the other. The typical forms of diphtheria and diphtheroid bacilli are of course widely separated, but there have been found in the course of this study a number of cultures which showed one or more of the properties considered characteristic of diphtheroids (e.g., chromogenesis, or fermentation of saccharose) while in other properties resembling the usual diphtheria bacillus. One of these strains produced sufficient toxin to kill a guinea-pig within two days when injected in a dose of 0.1 c.c.
SECOND SUBGROUP. THE SO-CALLED DIPHTHEROIDS AND HOFMANN'S BACILLI. (MORPHOLOGICAL TYPES IV, $\mathrm{V}$, AND VI).

The members of this subgroup present certain general characteristics. Their morphology is distinctive. All that were collected during this work were gram-positive and non-motile. Neither the 
gram-negative diphtheroid bacilli described by Hamilton ${ }^{\mathrm{x}}$ nor the motile forms described by DeWitt ${ }^{2}$ have been observed in this study.

Neisser's granules were as a rule present in types IV and V, only five strains failing to produce them at the end of four days. In a number of cases, however, they developed late, being absent in 24-hour cultures, but numerous at the end of four days. Differences in the size and form of the granules were observed in the two types, as has been mentioned. No granules were found in type VI.

On serum, the majority of the strains produced heavy salmonpink, yellow, or yellow-white growths. Colonies of the primary growth frequently were invisible for several days, but replants usually grew quickly and abundantly. Some strains, however, showed only a slow, scanty, colorless growth.

All the organisms were isolated from the human body, where these bacilli are not infrequently found in a variety of situations, both in normal and in pathological conditions. They probably would be found more often if routine cultures were examined again after the lapse of several days or a week.

The characteristics on which further subdivisions of this group are based are fermentation reactions, vigor of growth, and chromogenesis.

The curves of acid-formation in dextrose, maltose, and saccharose are alone significant, as dextrin is not acted upon by any of the organisms and glycerin only by a few of type $\mathrm{V}$.

In dextrose broth (Chart 8), two groups are apparent, one nonacid, the other highly acid. Between these there are numerous intergrading forms. The first group comprises type VI, and a few strains mostly of type IV, the second, the majority of IV and V.

The curve in maltose broth (Chart 8) likewise shows two groups: an alkaline and faintly acid group, and an acid group, with its mode at 2.0-2.5 per cent. In the first and largest group are classes III and most of IV; in the second class V and a few of IV.

The curve in saccharose broth (Chart 8) has two sharply defined modes, one alkaline, the other at $3 \cdot 0^{-} 3 \cdot 5$ per cent acid. Around the first mode are gathered types VI and V, while around the second is type IV.

× Jour. Infect. Dis., 1907, 4, p. 326.

2 Ibid., 191 2, 10, p. 36 . 
A study of the relation of surface growth and chromogenesis to these curves helps to bring out the grouping. In dextrose broth Io, or $5^{\circ}$ per cent, of the poorly growing strains are either alkaline or below I per cent acidity (Table II). Of the heavily growing

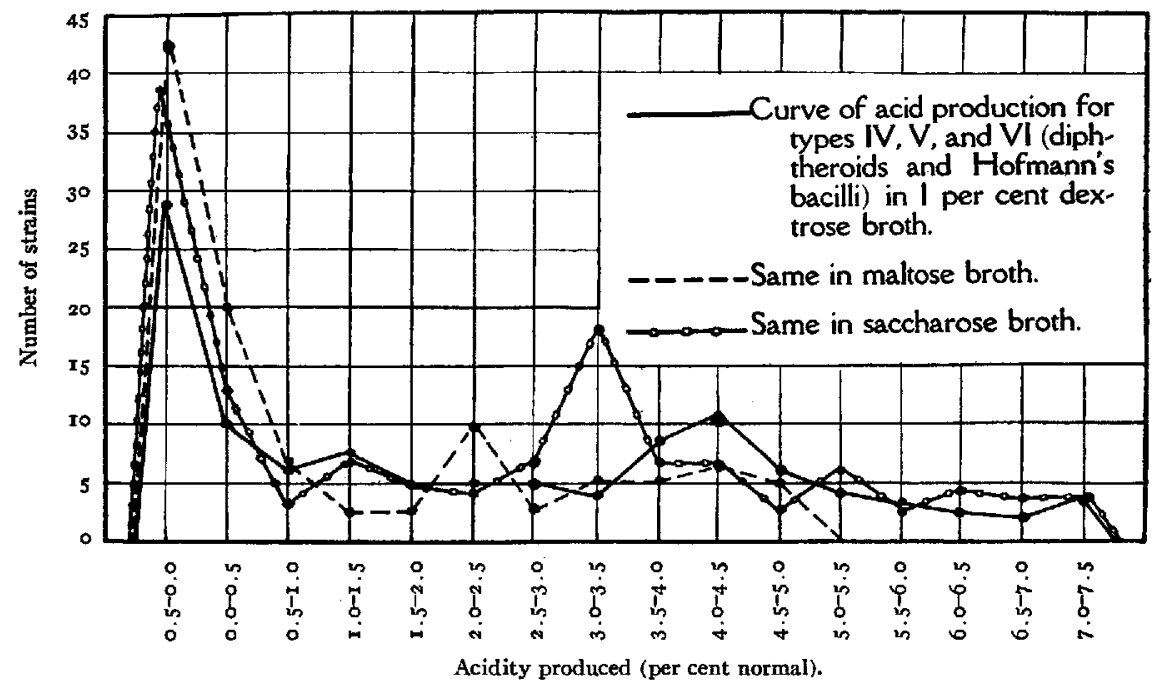

Chart 8.

cultures, 32, or 40 per cent, fall below I per cent and 29 , or 36 per cent, above 3 per cent acidity. The majority of the low-acid, heavily growing cultures belong to type VI, which shows wide variation in

TABLE II.

Correlation between Vigor of Growth and Fermentation of Dextrose. Actd Produced (Percentage Normal).

\begin{tabular}{|c|c|c|c|c|c|c|}
\hline & \multicolumn{6}{|c|}{ Number of Cultures in Each Cuass } \\
\hline & $\begin{array}{c}\text { Alkaline } \\
-0.0\end{array}$ & $0.0-1.0$ & $1.0-2.0$ & $2.0-3.0$ & $3.0-4.0$ & $\begin{array}{c}\text { Above } \\
4.0\end{array}$ \\
\hline $\begin{array}{l}\text { Scanty . . . . . . } \\
\text { Medium . . . . . } \\
\text { Heavy . . }\end{array}$ & $\begin{array}{r}9 \\
2 \\
25\end{array}$ & $\begin{array}{l}\mathbf{1} \\
0 \\
7\end{array}$ & $\begin{array}{l}5 \\
7 \\
8\end{array}$ & $\begin{array}{r}2 \\
0 \\
x\end{array}$ & $\begin{array}{l}2 \\
2 \\
7\end{array}$ & $\begin{array}{r}\mathbf{I} \\
3 \\
22\end{array}$ \\
\hline
\end{tabular}

abundance of growth; the remainder belong to type IV. The heavily growing, high-acid group is composed of chromogenic cultures, chiefly yellow and salmon-pink, of types IV and V. 
Correlation between degrees of surface growth and fermentation of maltose (Table 12 ) shows that 16 , or 75 per cent, of the scantily growing forms are below I per cent acidity, and also $5^{\circ}$, or 74 per cent, of the heavily growing strains. Here again, the scantily growing organisms belong to type VI, the heavily growing to types IV and VI. The acid-producers are of type V.

TABLE 12.

Correlation between Vigor of Growth and Fermentation of Maltose. Actorty Produced (Percentage Normal).

\begin{tabular}{|c|c|c|c|c|c|c|}
\hline & \multicolumn{6}{|c|}{ Numbers of Cultures in Each Class } \\
\hline & $\begin{array}{c}\text { Alkaline } \\
-0.0\end{array}$ & $0.0-1.0$ & I. $0-2.0$ & $2.0-3.0$ & $3.0-4.0$ & $\begin{array}{c}\text { Above } \\
4.0\end{array}$ \\
\hline $\begin{array}{l}\text { Scanty......... } \\
\text { Medium . . } \\
\text { Heavy .... }\end{array}$ & $\begin{array}{r}10 \\
2 \\
46\end{array}$ & $\begin{array}{l}6 \\
0 \\
4\end{array}$ & $\begin{array}{l}\mathbf{I} \\
0 \\
3\end{array}$ & $\begin{array}{l}0 \\
I \\
G\end{array}$ & $\begin{array}{l}3 \\
\text { I } \\
4\end{array}$ & $\begin{array}{l}0 \\
3 \\
4\end{array}$ \\
\hline
\end{tabular}

The table of relationship between surface growth and fermentation of saccharose (Table I3) shows that i 1 of the poorly growing strains are below I per cent, and only three above 2 per cent acidity. The heavily growing organisms are gathered at the two ends of the scale. The scantily growing non-acid strains are, as previously, of type VI, while the heavily growing non-acid group is composed of types V and VI. The highly acid group is formed by type IV.

TABLE I3.

Correlation between Vigor of Growth and Fermentation of Saccharose. Acdo Produced (Percentage Normal).

\begin{tabular}{|c|c|c|c|c|c|c|}
\hline & \multicolumn{6}{|c|}{ Number of Cultures in Eace Class } \\
\hline & $\underset{-0.0}{\text { Alkaline }}$ & $0.0-1.0$ & I. $0-2.0$ & $2.0-3.0$ & $3.0-4.0$ & $\begin{array}{c}\text { Above } \\
4.0\end{array}$ \\
\hline 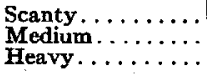 & $\begin{array}{r}9 \\
6 \\
27\end{array}$ & $\begin{array}{l}2 \\
3 \\
5\end{array}$ & $\begin{array}{l}5 \\
I \\
5\end{array}$ & $\begin{array}{r}0 \\
0 \\
11\end{array}$ & $\begin{array}{r}2 \\
\mathbf{I} \\
\mathbf{I} 8\end{array}$ & $\begin{array}{r}1 \\
2 \\
22\end{array}$ \\
\hline
\end{tabular}

Taking up chromogenesis more in detail, it is seen from Table I4, that nearly all of the colorless strains grew poorly, while the yellow-white, yellow, and salmon-pink cultures grew abundantly. The white strains were intermediate in position. 
Correlations between chromogenesis and acid-production in dextrose, maltose, and saccharose are significant in grouping the organisms.

TABLE I4.

Corkelation between Vigor of Growth and Chromogenesis

\begin{tabular}{|c|c|c|c|c|c|}
\hline & \multicolumn{5}{|c|}{ Number of Cultures in Each Class } \\
\hline & Colorless & White & Yellow-white & Yellow & Salmon-pink \\
\hline $\begin{array}{l}\text { Scanty. } \\
\text { Medium. } \\
\text { Heavy.. }\end{array}$ & $\begin{array}{r}\mathbf{r}_{3} \\
\mathbf{T} \\
\mathbf{I}\end{array}$ & $\begin{array}{l}5 \\
3 \\
8\end{array}$ & $\begin{array}{r}\mathbf{I} \\
2 \\
\mathbf{1 9}\end{array}$ & $\begin{array}{r}0 \\
2 \\
\text { II }\end{array}$ & $\begin{array}{r}\circ \\
\circ \\
4 \mathrm{I}\end{array}$ \\
\hline
\end{tabular}

In dextrose broth (Table 15) 60 per cent of the colorless and 70 per cent of the white strains fall below I per cent acidity. These represent type VI. The yellow-white cultures show an even distribution from alkaline to high acidities. The non-acid yellowwhite strains belong to type VI, while the acid-producers are allied in other characteristics to the next group, the yellow, all of which are above I per cent acidity. The salmon-pink cultures show a wide range of acidity, 30 per cent being below I per cent acidity, 24 per cent from $I$ to 3 per cent, and 46 per cent above 3 per cent acidity.

TABLE IS.

Correlation between Chromogenesis and Fermentation of Dextrose. Acid Produced (Percentage Normal).

\begin{tabular}{|c|c|c|c|c|c|c|}
\hline & \multicolumn{6}{|c|}{ Number of Cultures in Each Class } \\
\hline & $\begin{array}{c}\text { Alkaline } \\
-0.0\end{array}$ & $0.0-1.0$ & $1.0-2.0$ & $2.0-3.0$ & $3.0-4.0$ & $\begin{array}{c}\text { Above } \\
4.0\end{array}$ \\
\hline $\begin{array}{l}\text { Colorless.... } \\
\text { White...... } \\
\text { Yellow-white } \\
\text { Yellow . . } \\
\text { Salmon-pink. }\end{array}$ & $\begin{array}{l}7 \\
9 \\
5 \\
0 \\
6\end{array}$ & $\begin{array}{l}2 \\
1 \\
4 \\
0 \\
7\end{array}$ & $\begin{array}{l}3 \\
\mathrm{I} \\
2 \\
1 \\
7\end{array}$ & $\begin{array}{l}2 \\
0 \\
4 \\
1 \\
4\end{array}$ & $\begin{array}{l}\mathbf{I} \\
2 \\
3 \\
\mathbf{I} \\
6\end{array}$ & $\begin{array}{r}0 \\
1 \\
5 \\
7 \\
15\end{array}$ \\
\hline
\end{tabular}

In maltose broth (Table I6) the distribution of the colorless, white, and yellow-white strains is similar to that in dextrose broth, 83 per cent and 70 per cent of the colorless and white cultures respectively, giving less than I per cent acidity. Of the yellow strains five out of seven are decided acid producers. On the other hand, 86 per cent of the salmon-pink cultures fall below I per cent acidity. 
In saccharose broth (Table I7) also, the majority of the colorless and white strains ( 60 per cent and 84 per cent, respectively) give less than I per cent acidity. Of the yellow cultures, 66 per cent

TABLE 16.

Correlation between Chromogenests and Fermentation of Maltose. Acio Produced (Percentage Normal).

\begin{tabular}{|c|c|c|c|c|c|c|}
\hline & \multicolumn{6}{|c|}{ Number of Cultures n Each Class } \\
\hline & $\underset{-0.0}{\text { Alkaline }}$ & $0.0-1.0$ & 1.0-2.0 & $2.0-3.0$ & $3 \cdot 0-4 \cdot 0$ & $\begin{array}{c}\text { Above } \\
4.0\end{array}$ \\
\hline $\begin{array}{l}\text { Colorless. . . . . . } \\
\text { White . . . . . } \\
\text { Yellow-white. . } \\
\text { Yellow . . . . . } \\
\text { Salmon-pink. . . }\end{array}$ & $\begin{array}{r}3 \\
3 \\
2 \\
1 \\
30\end{array}$ & $\begin{array}{l}7 \\
7 \\
4 \\
I \\
7\end{array}$ & $\begin{array}{l}\mathbf{I} \\
\mathbf{I} \\
\mathbf{I} \\
0 \\
\mathbf{I}\end{array}$ & $\begin{array}{l}0 \\
0 \\
3 \\
1 \\
3\end{array}$ & $\begin{array}{l}\mathbf{I} \\
\mathbf{2} \\
\mathbf{r} \\
3 \\
\mathbf{I}\end{array}$ & $\begin{array}{l}0 \\
\mathbf{I} \\
4 \\
\mathbf{I} \\
\mathbf{I}\end{array}$ \\
\hline
\end{tabular}

are alkaline, the remainder are above 2 per cent acidity. The salmon-pink cultures show here the reverse of their action in maltose broth, i.e., 70 per cent give more than 3 per cent acidity.

TABLE $\mathbf{7 7}$.

Correlation between Chromogenesis and Fermentation of Saccharose. Acid Produced (Percentage Normat).

\begin{tabular}{|c|c|c|c|c|c|c|}
\hline & \multicolumn{6}{|c|}{ Number of Cultures in Each Class } \\
\hline & $\begin{array}{c}\text { Alkaline } \\
-0.0\end{array}$ & $0.0-\mathbf{r} .0$ & I.0-2.0 & $2.0-3.0$ & $3.0-4.0$ & $\begin{array}{c}\text { Above } \\
4.0\end{array}$ \\
\hline 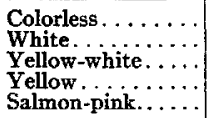 & $\begin{array}{r}2 \\
10 \\
8 \\
10 \\
2\end{array}$ & $\begin{array}{r}\mathbf{1} 4 \\
6 \\
3 \\
0 \\
3\end{array}$ & $\begin{array}{l}2 \\
2 \\
4 \\
0 \\
3\end{array}$ & $\begin{array}{l}0 \\
0 \\
3 \\
\mathbf{r} \\
6\end{array}$ & $\begin{array}{r}\mathbf{1} \\
\mathbf{1} \\
5 \\
\mathbf{1} \\
\mathbf{1} 6\end{array}$ & $\begin{array}{r}1 \\
0 \\
2 \\
3 \\
18\end{array}$ \\
\hline
\end{tabular}

It is apparent from the preceding analysis, first, that the colorless and white cultures show two subdivisions, a small acidproducing group, having a meager growth on serum, and a more abundantly growing group, of morphological type VI, which does not act on dextrose, maltose, saccharose, or glycerin; second, that the salmon-pink strains all grow heavily, are of morphological type IV, and usually ferment dextrose and saccharose, but not maltose or glycerin; third, that the yellow cultures belong to type $V$, grow heavily, and act on dextrose, glycerin, and maltose, but not on saccharose. 
Further study of the colorless and white cultures which produced acid shows that they all grew slowly and scantily, that they usually belonged to morphological type $\mathrm{V}$, that they all fermented dextrose, 77 per cent fermented maltose, and 72 per cent saccharose.

From this mass of detail concerning the diphtheroids, four groups stand out plainly. These may be defined as follows:

Group $A$.-This is the largest numerically. The bacilli correspond to the "organism $x$ " described by Hoag ${ }^{\mathrm{r}}$ from the Danvers State Hospital. It is a medium-sized bacillus, showing solid, barred, and wedge forms, with abundant but small and imperfect granules. On serum it produces a very heavy, confluent, glistening growth with a characteristic salmon-pink color. It ferments dextrose and saccharose, but not maltose or glycerin.

Group B.-The organisms of this group are usually larger than those of Group A, and thick forms with clear-cut bars predominate. Neisser's granules are very large and irregular. The growth on serum is heavy and varies in color from white to yellow. It is often noticeably dry and granular. Dextrose is always fermented, maltose and glycerin usually, but not saccharose.

Group C.-This, the smallest group, is differentiated primarily by its slow, scanty, colorless, or white growth. Morphologically, the organisms resemble Group B. They always acidify dextrose, and usually both maltose and saccharose.

Group D.-Composed of small, thick, straight bacilli, often barred and wedgeshaped, showing no granules. The growth on serum may be scanty or abundant and is white or yellow-white in color. They do not act upon dextrose, maltose, glycerin, or saccharose.

The members of Group B resemble the typical diphtheria bacillus in fermentation reactions more closely than members of the other groups, as both acidify dextrose and maltose but not saccharose. On the other hand, as has been said, certain intermediate strains of diphtheria bacilli are closely allied morphologically and culturally to Group A. Group D is obviously identical with Hofmann's bacillus. The xerosis bacillus corresponds in manner of growth and in fermentation reactions to members of Group C.

In regard to names for these species, it would seem that $B$. hoagii is appropriate for Group $\mathrm{A}$, because the first extended description of it was given by Hoag, although bacilli apparently identical with it have been mentioned occasionally in the literature.

The salient characteristic of Group B, in addition to its fermentation reactions, is the yellow or yellow-white color of the cultures. The name $B$. flavidus might, therefore, be given to this species.

- Boston Med. and Surg. Jour., 1907, 157, p. 10. 
For Group C, it would appear best to retain the familiar name $B$. xerosis, limiting it, however, to bacilli showing the cultural and fermentative peculiarities of this group.

$B$. hofmanni is of course the rightful name for Group D.

The term "pseudo-diphtheria bacillus" is used with different meanings by different authors, some limiting it to Hofmann's bacillus and others applying it indiscriminately to any organisms resembling morphologically the diphtheria bacillus. The nomenclature here suggested eliminates this equivocal term.

Previous classifications of the diphtheroids have not been lacking, but they have been concerned chiefly with Hofmann's bacillus and the xerosis bacillus. Isolated strains of diphtheroids have been described and have been named from slight peculiarities in morphology, etc. Pyogenic forms have occasionally been mentioned. Classification has usually been based on morphology and the character of the growth on agar and gelatin, together with acid-production in glucose broth. Lehmann and Neumann ${ }^{\mathrm{I}}$ group the pseudo-diphtheria and diphtheroid bacilli with the diphtheria bacillus as corynebacteria, making the groups of Coryn. diphtheriae; Coryn. pseudodiphtheriticus, "which includes the luxuriantly, succulently, and rapidly growing non-virulent forms," and Coryn. xerosis, which designates the scantily and delicately growing varieties.

Hamilton ${ }^{2}$ alone has differentiated groups based on fermentation reactions. She describes two groups of "pseudo-diphtheria bacilli" frequently found in suppurative processes, which are the same as groups A and B of the present study. She observed the same morphological and fermentative differences as are here described, but does not mention chromogenesis. Group B she considers very closely related to the true Klebs-Loeffler organism.

Although considerable experimental work has been done on B. paralyticans ${ }^{3}$ there appears to be in the literature no account of its fermentation reactions, except that it acidifies dextrose. During the present study a culture of this organism was obtained from Dr. Jessie W. Fisher of the Connecticut State Hospital, who

: Bacteriology, I90I, 2, p. 404 .

Jour. Infect. Dis., rgo7, 4, p. 326.

3 Robertson, W. F., and McRae, G. D., Rev. of Neurol. and Psych., 1903, I, pp. 225, 305. 
had received it from Dr. Ford-Robertson. It produced on serum, at the end of 24 hours, an abundant growth of isolated, moist, yellow-white colonies, the largest being $\mathrm{I} \mathrm{mm}$. in diameter. The growth was more translucent than that of $B$. diphtheriae. Morphologically, the organism was a large barred bacillus, often with tapering ends, and with numerous well-formed granules. The arrangement usually was parallel, and the bacillus was thicker and less curved than $B$. diphtheriae. At the end of four days the bacilli were fused into poorly staining masses, and no Klebs-Loeffler involution forms had developed. The bacillus formed much acid from dextrose, maltose, and saccharose, but did not affect glycerin or dextrin. It is apparent that this organism does not correspond in all its characteristics to any one of the groups. Its morphology, growth on serum, and action on maltose ally it to Group B, but contrary to the rule in this group it ferments saccharose.

Quite a number of the strains of diphtheroids investigated during this work were isolated from the lochia in puerperal infections, from the cervical discharge in pelvic inflammatory cases, and from vaginitis in children. Organisms which doubtless belong to this group have been found by Hallè ${ }^{x}$ and by Foulerton and Bonney $^{2}$ in cases of puerperal fever, but it would seem that the frequency of these bacilli in the genital tract and their possible relation to gynecological infections has not been generally recognized. In our series, the bacilli were associated with streptococci in three cases, with staphylococci in ten, with gonococci in eight, while in eight cases no other bacteria were found in the smear or culture. In a series of control cultures from the cervix in pregnant and puerperal women with no pelvic lesions, the bacilli were not found. Their presence without other organisms suggests that in some instances they may be the cause of a mild inflammation in these situations. This point has not been investigated further. Diphtheroid bacilli in inflammatory processes usually have been regarded as saprophytes or harmless secondary invaders. Hamilton, however, believes that they play an important part in the causation of otitis media, especially the post-scarlatinal variety,

- Ann. de Gynec. et Obst., 1899, 51, pp. 113, 195, 295

- Trans., Path. Soc. London, 1903, 54, p* 139. 
because they were found in $7^{2}$ per cent of 43 cases of acute scarlatinal otitis media, and in 20 per cent of these cases in pure culture; also because the opsonic index of the patients for these bacilli showed marked variations, and the injections of corresponding vaccines modified definitely the course of the infection.

\section{CONCLUSIONS.}

I. The diphtheria bacillus, Hofmann's bacillus, and the "diphtheroids" form one family.

2. The family is divided into two main subgroups, the first comprising the diphtheria bacillus, the second the "diphtheroids" and Hofmann's bacillus.

3. In the first group, it does not appear that any further differentiation can be made, except between the virulent forms and the non-virulent, which tend to have a heavier growth, more marked chromogenesis, more solid-staining forms, and lessened acidproduction. The organisms of this group form a continuous series, and may well be retained under the species $B$. diphtheriae, and designated only as the virulent and non-virulent varieties.

4. The second subgroup can be further divided, on the basis of morphology, chromogenesis, fermentation reactions, and vigor of growth, into four species. These comprise the diphtheroids frequently found on the human body. In addition to the names $B$. xerosis and $B$. hofmanni, which are in common use, the terms $B$. hoagii and $B$. flavidus are suggested for these species.

Following is a table showing the characteristics of the five species in the diphtheria group. 
Study of Diphtheria Group by Biometrical Method 285

\begin{tabular}{|c|c|c|c|c|c|c|}
\hline \multirow{2}{*}{ 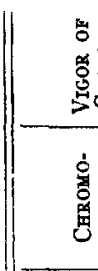 } & 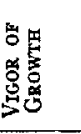 & 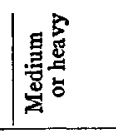 & 总 & 惑 & $\begin{array}{l}\text { 害 } \\
\text { 员 }\end{array}$ & 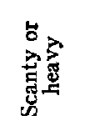 \\
\hline & 递 & 窎 & 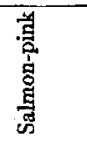 & 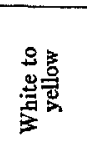 & 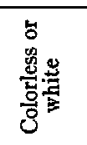 & 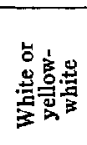 \\
\hline \multicolumn{2}{|c|}{ 总䍗 } & + & 1 & 1 & 1 & 1 \\
\hline \multicolumn{2}{|c|}{ 总总总 } & + & 1 & 1 & 1 & 1 \\
\hline \multirow{5}{*}{ 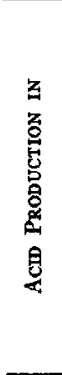 } & 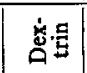 & $H$ & 1 & 1 & I & 1 \\
\hline & 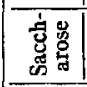 & 1 & + & 1 & + & 1 \\
\hline & 혛몁 & + & 1 & + & H & I \\
\hline & 焉品 & + & 1 & + & + & 1 \\
\hline & $\mid \dot{g}$ & $1+$ & + & + & + & 1 \\
\hline \multicolumn{2}{|c|}{ 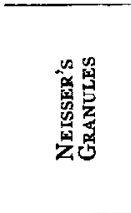 } & + & 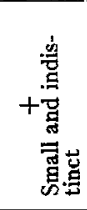 & 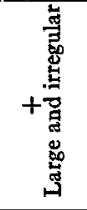 & 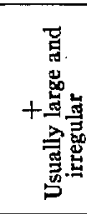 & 1 \\
\hline \multicolumn{2}{|c|}{ 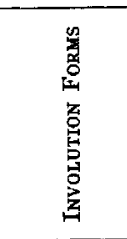 } & 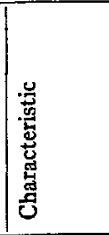 & 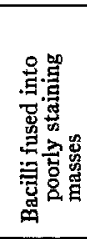 & 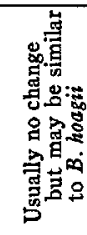 & 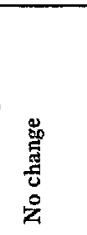 & 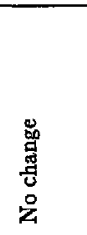 \\
\hline \multirow{2}{*}{\multicolumn{2}{|c|}{$\begin{array}{l}\text { 范 } \\
\text { 总 } \\
\text { 农 }\end{array}$}} & 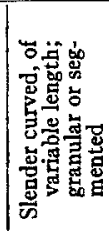 & 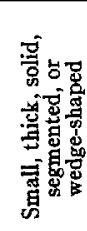 & 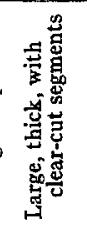 & 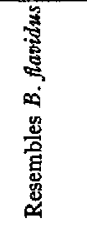 & 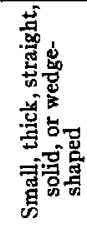 \\
\hline & & 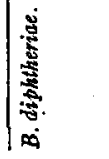 & 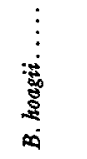 & 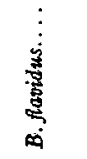 & 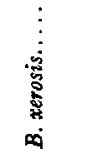 & $\frac{n}{3}$ \\
\hline
\end{tabular}

